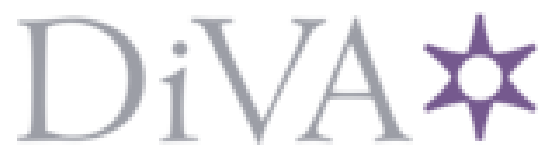

http://www.diva-portal.org

This is the published version of a paper published in .

Citation for the original published paper (version of record):

Rajeev, B., Prasad, K., Shetty, P J., Preet, R. (2017)

The relationship between orofacial clefts and consanguineous marriages: A hospital registerbased study in Dharwad, South India.

, 4(1): 3-8

https://doi.org/10.4103/2348-2125.205410

Access to the published version may require subscription.

N.B. When citing this work, cite the original published paper.

Permanent link to this version:

http://urn.kb.se/resolve?urn=urn:nbn:se:umu:diva-134358 


\title{
The relationship between orofacial clefts and consanguineous marriages: A hospital register-based study in Dharwad, South India
}

\author{
Rajeev B. R., K. V. V. Prasad, Preetha J. Shetty, Raman Preet ${ }^{1}$
}

DOI:

$10.4103 / 2348-2125.205410$

\section{ABSTRACT}

Context: Orofacial cleft (OFC) is one of the common craniofacial malformations. The etiology of these OFCs is multifactorial. One of the etiological factors is consanguinity (marriage between blood relatives). There is a lack of literature reporting the number of people affected with OFCs due to consanguinity. Aims: The aim of this study is to report the occurrence of OFC and associated factors in relation to consanguinity from a craniofacial hospital specializing in OFCs, head and neck cancer, and trauma management in South India. Setting and Design: This was a hospital-based study, retrospective case record analysis. Methodology: One thousand two hundred and forty-seven consecutive patients' secondary data records with cleft lip (CL), cleft palate $(C P)$ and cleft lip and palate (CL/P) were collected from January 2007 to July 2009. Statistics: Frequency of consanguinity in relation to OFC was analyzed using Chi-square test according to the nature of clefts and selected demographic features such as sex, region, and religion. Results: A total of $47.2 \%$ patients' parents had consanguineous marriage. Consanguinity was seen in $60.2 \%$ of male and $39.7 \%$ of female patients. $\mathrm{CL} / \mathrm{P}$ was noticed in $40.9 \%$, followed by CL $(36.7 \%)$ and CP $(22.2 \%)$. Males predominated in all types of clefts proportionally with the study population as compared to females. Statistically, significant association $(P=0.04)$ was seen with consanguinity and CP. Conclusion: Nearly half of the study population had a positive history of consanguinity. Statistically, a significant association was seen between $\mathrm{CP}$ and consanguinity. CL/P cases were the most common type identified, followed by CL and CP. Males predominated in all types of clefts. The

Department of Public Health Dentistry, SDM College of Dental Sciences and Hospital, Rajiv Gandhi University of Health Sciences, Bengaluru, Karnataka, India, ${ }^{1}$ Unit of Epidemiology and Global Health, Department of Public Health and Clinical Medicine,

Faculty of Medicine, Umeå University, Umeå, Sweden

Address for correspondence:

Dr. Rajeev B. R.,

Department of Public Health Dentistry, SDM College of Dental Sciences and Hospital, Dharwad - 580 009,

Karnataka, India.

E-mail: rajeevbasapathy@gmail.com prevalence of OFC is high, and there is a potential of congenital disabilities from consanguinity. These findings indicate a clear and urgent need for setting up a National Registry of Congenital Anomalies along with craniofacial defects, to monitor these trends and the corresponding need for supportive services.

Key words: Cleft lip, cleft palate, consanguinity, orofacial clefts, South India

\section{INTRODUCTION}

Craniofacial congenital disabilities such as cleft lip (CL), cleft palate (CP), and cleft lip and palate (CL/P) grouped under orofacial cleft (OFC) are the most common of all the developmental disorders affecting humans. ${ }^{[1]}$ The incidence and prevalence of OFC vary throughout the world. The epidemiological data on an international perspective are varied, and many countries lack these data. ${ }^{[2]}$ The estimated global prevalence of CL/P is one in every 600 newborn babies. ${ }^{[3]}$ Although there are few studies which describe the prevalence of OFC in India, the most recent data indicate the incidence to be 1.09/1000 live births ${ }^{[4]}$ whereas Mossey and Little ${ }^{[3]}$ reported the prevalence being at 28,600 throughout the country.

The nonsyndromic OFC is a polygenic multifactorial disorder. CL/P is a multifactorial disorder with multiple risk factors such as genetics, environmental causes,

\footnotetext{
This is an open access article distributed under the terms of the Creative Commons Attribution-NonCommercial-ShareAlike 3.0 License, which allows others to remix, tweak, and build upon the work non-commercially, as long as the author is credited and the new creations are licensed under the identical terms.
}

For reprints contact: reprints@medknow.com

Cite this article as: Rajeev BR, Prasad K, Shetty PJ, Preet R. The relationship between orofacial clefts and consanguineous marriages: A hospital register-based study in Dharwad, South India. J Cleft Lip Palate Craniofac Anomal 2017:4:3-8. 
and cultural factors. The role of genetic factors in the etiology of CL/P is critical and it is associated with 400 different syndromes. In India, consanguineous marriages are not uncommon due to prevailing cultural practices. Consanguinity is an identified factor that increases the risk of transmission of genetic disorders, especially autosomal recessive ones. Consanguinity is a cultural practice which could have an epigenetic role in the development of congenital abnormalities. Hence, along with genetic and environmental factors such as consanguinity which is a cultural factor, it also contributes to CL/P's etiology. ${ }^{[5]}$ A meta-analysis revealed an odds ratio of 1.83 (95\% confidence interval, 1.31-2.54) implying the risk of having cleft two times higher in children with consanguineous history. ${ }^{[6]}$ Consanguineous marriages are a common social norm in many societies worldwide where marriages are between close blood-related persons varying from first cousins to uncle-niece relations. About $10.4 \%$ of couples in the global population are reported to be related as the second cousins or closer; a similar relationship holds true for the progeny of these couples. ${ }^{[7]}$ Consanguinity is practiced commonly in Arab Countries (50\%), South India (10\%-50\%); China, North India, Latin America, Japan, South Europe (10\%) and less common in the United States, Russia, Australia, Parts of Latin America, and Europe (1\%). ${ }^{[8]}$

Bittles and Black ${ }^{[7]}$ have reported that consanguinity is a much wider and more complex issue involving major economic, demographic, and social influences, differential reproductive behavior, and early- and late-onset morbidity and mortality. The influence of consanguinity on the etiology of congenital anomalies is a common observation. Kulkarni and Kurian ${ }^{[9]}$ have reported that consanguinity has a probable deleterious effect on fetal growth and an increased risk of congenital malformations and fetal loss. Several studies have shown significant associations between consanguinity and congenital anomalies. ${ }^{[10-12]}$

Consanguinity and its effect on OFC have been studied and reported extensively. Some observational studies showing an association between OFC and consanguinity have been reported from arab countries. However, only few studies have been reported from India. ${ }^{[17,18]}$ There is a dearth of recorded data or literature supporting the relation of consanguinity and OFC in India. Therefore, the purpose of this study was to evaluate the relationship between consanguineous marriages and patterns of CL and CP from data collected in a craniofacial hospital in South India. The objectives are to estimate the proportion of different types of OFCs presenting to a tertiary care hospital in
South India and to describe the demographic profiles (including gender, region, religion, and consanguinity) in these patients.

\section{METHODOLOGY}

A retrospective analysis of a prospectively collected database of all CL/P patients treated in the craniofacial hospital at SDM College of Dental Sciences and Hospital, Dharwad, India. The hospital is a superspecialty tertiary care center of craniofacial abnormalities and rehabilitation. Every OFC case details are entered into a database since 1991. The present study included a retrospective analysis in 2013 of patient records for a 30-month period between January 2007 and July 2009. This tertiary care level hospital is located in the northwestern part of Karnataka of Southern India. The surgical treatment provided here is free of cost under the auspices of the Smile Train India Project. The patient pool is large and attracts patients mostly from North Karnataka and also from the neighboring states of Goa, Maharashtra, and Andhra Pradesh. SDM College of Dental Sciences and Hospital's Institutional Review Board approved this study.

A total of 1247 patient records were audited and used to form the basis of the study. The hospital records included data about demographic details such as age, sex, address (urban/rural), religion, family type (joint/ nuclear), parent's education, occupation and monthly income; presence or absence of consanguinity, type of clefts, age of mother at first conception, and any other sibling with OFC and their cleft type. The present study specifically collected data regarding selected demographic features such as sex, region, religion, history of consanguinity, and cleft type. Each patient record was assigned an individual outpatient number, and care was taken not to count the same patient more than once. Patient records/information were anonymized and de-identified before analysis.

A simple descriptive classification was used to record the cleft type. CL was further classified into unilateral and bilateral and CP into partial and complete. CL/P was also classified into unilateral (CL/P U/L) and bilateral.

The information was collected manually and entered into a Microsoft Excel sheet by the investigator. Data were subjected to descriptive statistical analysis using Microsoft Excel and were further analyzed using Version 20 (IBM Corp. Released 2011. IBM SPSS Statistics for Windows, Version 20.0. Armonk, NY: IBM Corp). The association of OFC with consanguinity, gender, region, 
religion and cleft type was analyzed using univariate analysis such as Chi-square test.

\section{RESULTS}

Table 1 shows the demographic features. There were 766 males and 481 females, with a male-female ratio of 1.5:1. Clefts were seen more in rural settings (1076, 86.2\%) compared to urban (171, 13.7\%). Hindu patients $(1049,84.1 \%)$ showed the highest rate of OFC. A total of 589 subjects' parents had consanguineous marriage (47.2\%). Among the consanguineous group of the study population, a majority were from a rural (508, $86.2 \%)$ as compared to an urban setting $(81,13.7 \%)$. Among consanguineous progeny, most were Hindus (509, 48.5\%), followed by Muslims (76, 40\%), Christians (2, 0.33\%), and Buddhists and Jains (each one subject). The male-female ratio with consanguinity was 1.5:1. CL/P was most common $(511,40.9 \%)$, followed by CL (458, $36.7 \%)$ and CP (278, 22.2\%). Males predominated in all types of clefts proportionally in the study population compared to females [Table 2]. Unilateral CL (195, 33.1\%) was more commonly associated with consanguinity, followed by CL/P U/L (186, 31.5\%).

A statistically significant association $(P=0.04)$ was seen with consanguinity and CP [Table 3]. Data related to parent's education and occupation and monthly income were missing in some records. These data were not considered in the present study as they were not related to the aims and objectives. A total of 24 patients had siblings with CL/P. From the total sample, 91 patients' (7.29\%) parents gave a family history of $\mathrm{CL} / \mathrm{P}$.

\section{DISCUSSION}

Consanguineous unions have been practiced since time immemorial. They began as a necessity due to small populations that existed during primitive times and were practiced in most parts of the world until the early $19^{\text {th }}$ century. The merits and demerits of this practice have been a debated topic. Although consanguineous marriages are declining globally, it is still widely practiced in the Middle Eastern countries such as Saudi Arabia, Iran and also in Southern India. ${ }^{[8]}$ There is a wide geographical distribution and variations in consanguineous marriages globally. This marriage system between close biological relations involves many social, cultural, religious, and civil aspects. ${ }^{[7,10,11]}$ The practice of consanguinity within the Indian subcontinent shows similar differences as those observed in other parts of the world. In India, this practice is an accepted method of union between two persons and is accepted culturally, socially, religiously, and also legally particularly in the southern states.

Consanguinity is widely practiced by the Dravidian Hindus and less commonly among the Muslims of South Indian states such as Andhra Pradesh, Karnataka, and Tamil Nadu. ${ }^{[19,20]}$ Bittles et al. reported that in Bengaluru and Mysore, two major cities of Karnataka of South India, $21 \%$ of Hindu marriages were uncle-niece unions. ${ }^{[1]}$ Although a $1 \%$ decline in consanguineous marriages throughout the country was observed from 1960 to the 1990s, there have been no recent data on its prevalence; however, another study found that there was no declining trend in the immigrant Mudaliar community

\begin{tabular}{|c|c|c|c|c|}
\hline \multicolumn{5}{|c|}{ Table 1: Demographic Profile of the Study Population } \\
\hline Demogra & atures & Study Population (\%) 1247 & Consanguineous (\%) 589 (47.2) & Non consanguineous $(\%) 658$ \\
\hline \multirow[t]{2}{*}{ Gender } & Males & $766(61.4)$ & $355(46.3)$ & $411(53.6)$ \\
\hline & Females & $481(38.5)$ & $234(48.6)$ & $247(51.3)$ \\
\hline \multirow[t]{2}{*}{ Region } & Urban & $171(13.7)$ & $81(47.3)$ & $90(52.6)$ \\
\hline & Rural & $1076(86.2)$ & $508(47.2)$ & $568(52.7)$ \\
\hline \multirow[t]{5}{*}{ Religion } & Hindus & $1049(84.1)$ & $509(48.5)$ & $540(51.4)$ \\
\hline & Muslims & $187(14.9)$ & $76(40)$ & $111(60)$ \\
\hline & Christians & $6(0.4)$ & $2(0.33)$ & $4(0.6)$ \\
\hline & Buddhists & $2(0.1)$ & $1(0.5)$ & $1(0.5)$ \\
\hline & Jains & $3(0.2)$ & $1(0.3)$ & $2(0.6)$ \\
\hline
\end{tabular}

\begin{tabular}{|c|c|c|c|c|c|c|}
\hline \multirow[t]{2}{*}{ Gender $(n)$} & \multicolumn{2}{|c|}{ Cleft Lip (\%) } & \multicolumn{2}{|c|}{ Cleft Palate (\%) } & \multicolumn{2}{|c|}{ Cleft Lip and Palate (\%) } \\
\hline & Unilateral & Bilateral & Partial & Complete & CL/P U/L & CL/P B/L \\
\hline Male (766) & $250(32.6)$ & $20(2.6)$ & $94(12.2)$ & $60(7.8)$ & $264(34.4)$ & $78(10.1)$ \\
\hline Female (481) & $166(34.5)$ & $22(4.5)$ & $79(16.4)$ & $45(9.3)$ & $132(27.4)$ & $37(7.6)$ \\
\hline Total (1247) & $416(33.3)$ & $42(3.3)$ & $173(13.8)$ & $105(8.4)$ & $396(31.7)$ & $115(9.2)$ \\
\hline Grand Total & \multicolumn{2}{|c|}{$458(36.7)$} & \multicolumn{2}{|c|}{$278(22.2)$} & \multicolumn{2}{|c|}{$511(40.9)$} \\
\hline
\end{tabular}


Rajeev, et al.: Consanguinity and orofacial clefts

\begin{tabular}{|c|c|c|c|c|c|c|}
\hline \multirow[t]{2}{*}{ Consanguineous ( $n$ ) } & \multicolumn{2}{|c|}{ Cleft Lip } & \multicolumn{2}{|c|}{ Cleft Palate* } & \multicolumn{2}{|c|}{ Cleft Lip and Palate } \\
\hline & Unilateral & Bilateral & Partial & Complete & CL/P U/L & $\mathrm{CL} / \mathrm{P} \mathrm{B} / \mathrm{L}$ \\
\hline Yes (589) & $195(33.1)$ & $20(3.3)$ & $96(16.2)$ & $44(7.4)$ & $186(31.5)$ & $48(8.1)$ \\
\hline No $(658)$ & $221(37.5)$ & $22(3.7)$ & 77 (11.7) & $61(10.3)$ & $210(31.9)$ & $67(10.1)$ \\
\hline Total (1247) & $416(33.3)$ & $42(3.3)$ & $173(13.8)$ & $105(8.4)$ & $396(31.7)$ & $115(9.2)$ \\
\hline \multirow[t]{2}{*}{ Grand Total } & \multicolumn{2}{|c|}{$458(36.7)$} & \multicolumn{2}{|c|}{$278(22.2)$} & \multicolumn{2}{|c|}{$511(40.9)$} \\
\hline & \multicolumn{2}{|c|}{$\begin{array}{c}\chi^{2}=0.033 \\
P=0.98\end{array}$} & \multicolumn{2}{|c|}{$\begin{array}{c}\chi^{2}=6.234 \\
P=0.04\end{array}$} & \multicolumn{2}{|c|}{ 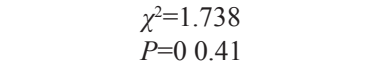 } \\
\hline
\end{tabular}

in Kerala, South India. ${ }^{[22]}$ This is in concordance with reports, suggesting the practice of consanguinity among Asian migrants in Europe to be common. ${ }^{[7]}$

The effects of consanguinity on health and disease have been studied and reviewed extensively. To the best of our knowledge, there are no previous studies reported from India, examining the relationship of consanguinity and the most common craniofacial congenital anomalies, particularly OFC. This study highlights the practice of consanguinity across India but more prevalent in South India, which is widespread throughout the country. The present study was conducted in Dharwad in South India. The craniofacial hospital attracts patients from a radius of 200-300 miles. Since the study's aim was to check the relationship between consanguinity and CL/P from hospital records, the interpretation of the findings is limited to the practice of consanguinity in relation to $\mathrm{CL} / \mathrm{P}$, which will also determine the prevalence of consanguinity. Consanguinity was identified during the case history recording and was done usually by the clinician orally. One of the major limitations of the study is that the details related to the degree of the consanguinity were not recorded. This was brought to the notice of the hospital administration, and they decided to include these details in the case history afterward.

In our study, consanguineous marriages were observed among $47.1 \%$ of patients' parents, which is less than what was observed by Aljohar et al. and Ravichandran et al., suggesting a lesser prevalence compared to Arab countries. ${ }^{[5,15,16]}$ On the contrary, consanguineous marriages were seen only in $36 \%$ of the study population conducted in the neighboring district of Belgaum of North Karnataka where consanguineous marriages are a common social norm. ${ }^{[23]}$ This could be due to the geographical variation in practice, as well as data availability being secondary and the changing attitudes and behavior toward consanguinity.

This study shows a high prevalence of consanguinity among rural population (86.2\%). Studies have reported that consanguinity is commonly practiced by people who are illiterate and from low socioeconomic status and other related factors. ${ }^{[5,10,24]}$ Rural areas show higher rates of illiteracy and low socioeconomic status in India. ${ }^{[25]}$ Despite the several negative consequences of the practice ranging from neonatal mortality to congenital anomalies with genetic mutations, consanguinity also offers certain social advantages seen in rural areas such as ease of enhanced female autonomy, marriage arrangements, more stable marital relationships, lower domestic violence, greater compatibility with in-laws, economic benefits of reduced dowry, lower divorce rates and maintenance of any landholding.

The present study showed a high prevalence of clefts (84.1\%) and consanguinity (86.4\%) among Hindus. This is in agreement with previous studies suggesting that consanguinity was common in Hindus. ${ }^{[10,22,26]}$ The OFC common in Hindus was again in harmony with results reported by Dvivedi and Dvivedi. ${ }^{[24]}$ The Hindu Code Bill of 1984 and the Hindu Marriage Act of 1955 support the legality of consanguineous marriages in India. ${ }^{[7]}$ The high prevalence rate in the Hindu religion is in proportion to the national population, which is about 80.5\% according to 2011 census. ${ }^{[27]}$

The results of the study also showed a high prevalence of OFC among males. Males predominated in all types of clefts proportionally with the study population compared to females. Aljohar et al..$^{[5]}$ reported that $\mathrm{CL} / \mathrm{P}$ and CL were more common in males and CP in females although Aljohar et al. reported that CP was indeed common in males. ${ }^{[15]}$ In contrast, our study found $\mathrm{CP}$ to be more common among males as compared to females. ${ }^{[4,5,16]}$

In the present study, CL/P (40.9\%) was seen more than CL and CP, which is consistent with the literature. CL (36.7\%) occurring more than CP (22.2\%) differs from the literature. ${ }^{[5,16]}$ A statistically significant association $(P=0.04)$ was seen with consanguinity and CP. Similar significant results were reported between consanguinity and OFC, ${ }^{[6,13,15,16,18]}$ whereas 
Golalipour et al. reported that no significant association was seen between consanguinity and OFC. ${ }^{[28]}$ This significance could indicate the biological plausibility between consanguinity and OFC, particularly CP. This significance is explained by other studies considering factors such as degree of consanguinity, ${ }^{[18]}$ ascertainment, ${ }^{[6]}$ family history of clefts, and intracluster correlation between siblings affected by OFC. ${ }^{[16]}$

Consanguineous marriages have been debated since Darwinian times. The advent of genetics and its application in medical sciences to diagnose and prevent disease has further broadened our knowledge in understanding effects of this practice on health and disease. Genetically, close biological unions result in expression of autosomal recessive genes which are associated with many congenital anomalies such as childhood deafness, congenital cataracts, heart defects, and craniofacial defects such as OFC $\cdot^{[7,11]}$ Although many studies show statistically significant associations between consanguinity and OFC, they do not prove the etiology of OFC to be consanguinity. Therefore, it necessitates further research to investigate this biological plausibility. Recently, a gene was identified as the causal mutation for $\mathrm{CL} / \mathrm{P}$ in consanguineous Palestinian families. ${ }^{[29]}$ As theorized, consanguinity could have a genetic effect. ${ }^{[16]}$ Bittles has discussed the relation between consanguinity and genetics and has concluded that in populations where consanguineous marriage is widely practiced, recessive genetic disorders will continue to gain greater prominence in the overall spectrum of ill health. ${ }^{[18]}$

Since the consanguineous marriage system is characterized by many variations such as region, religion, and caste, it is relevant to the general population. The marriage preferences such as choice of bride/groom, caste preference, and love marriage over arranged marriage all contribute to the increase or decrease of consanguinity. CL/P along with other congenital anomalies has varied etiological risk factors, of which consanguinity is thought be one. The results of this study provide valuable information regarding the prevailing consanguineous marriage system practice and are relevant considering the multiple risk factor etiology for CL and palate deformities. By knowing the prevalence, strategies to prevent and educate masses about the effects of consanguinity should be developed.

India does not have a national registry for congenital anomalies as per the recommendations of World Health Organization. This study helps us to build an evidence base that can be used for approaching the decision-makers for such a need in India focusing on congenital anomalies including craniofacial defects for a collaborative interdisciplinary research on database setup, epidemiology, gene-environment interaction and prevention..$^{[3,19,30-33]}$

\section{Strengths and limitations}

The primary author came across a large number of OFC patients during the graduate residency program which provoked the interest in researching on consanguinity and OFC. This study was conducted using hospital records as opposing to population-based study because of feasibility considerations such as cost and human resource. Since secondary data were collected using hospital records, the question of ascertainment arises. The validity and reliability of the data collected should be considered because the hospital registry-based studies are prone to bias. ${ }^{[30]}$ There is considerable variation in the frequencies of OFC worldwide and comparability of the data is affected by factors such as source of the sample population versus hospital-based studies, method of ascertainment, inclusion-exclusion criteria and sampling fluctuation. ${ }^{[2]}$ The present study's scope was limited to do a cross-sectional descriptive study to describe the relation of consanguinity and CL/P. For this reason, case-control design was not deemed appropriate for our objectives, and thus, control group was not included in this study.

The epidemiological data on OFC and its associated factors is lacking in India. ${ }^{[2]}$ There are no national-level studies conducted to find the prevalence of consanguinity. Therefore, the correlation of observed prevalence in this study to the general population prevalence is not possible.

\section{CONCLUSION}

From the present study, it can be concluded that nearly half of the study population was the progeny of a consanguineous union. The number of consanguineous marriages from this study showed the possible magnitude of its effects. There was statistically significant association seen between CP and consanguinity. CL/P was more commonly seen, followed by CL and CP. Males predominated in all types of clefts.

The prevalence of consanguinity and the burden of resulting congenital disabilities identified by this study demonstrate a clear and urgent need for creating a national registry for congenital anomalies, including craniofacial defects. This is based on the recommendations of the World Health Organization to facilitate collaborative, interdisciplinary research using case-control study design by collecting primary data. 
Such research will also contribute to a more robust understanding of epidemiology, gene-environment interaction and potential prevention strategies. Finally, strategies to prevent and educate masses about the effects of consanguinity should be developed.

This study was presented at the $17^{\text {th }}$ National conference of Indian association of Public Health Dentistry held at Chennai in November, 2012 and won best paper award.

\section{Acknowledgement}

We would like to thank Dr Nachiket Shankar, Department of Anatomy, St Johns National Academy of Medical Sciences, Bangalore, India for his valuable advice while interpreting the data.

\section{Financial support and sponsorship}

Nil.

\section{Conflicts of interest}

There are no conflicts of interest.

\section{REFERENCES}

1. Centers for Disease Control and Prevention (CDC). Economic costs of birth defects and cerebral palsy - United States, 1992. MMWR Morb Mortal Wkly Rep 1995;44:694-9.

2. Shaw W. Global strategies to reduce the health care burden of craniofacial anomalies: Report of WHO Meetings on International Collaborative Research on Craniofacial Anomalies. Cleft Palate Craniofac J 2004;41:238-43.

3. Mossey P, Little J. Addressing the challenges of cleft lip and palate research in India. Indian J Plast Surg 2009;42 Suppl 1:S9-18.

4. Reddy SG, Reddy RR, Bronkhorst EM, Prasad R, Ettema AM, Sailer HF, et al. Incidence of cleft Lip and palate in the state of Andhra Pradesh, South India. Indian J Plast Surg 2010;43:184-9.

5. Aljohar A, Ravichandran K, Subhani S. Pattern of cleft lip and palate in hospital-based population in Saudi Arabia: Retrospective study. Cleft Palate Craniofac J 2008;45:592-6.

6. Sabbagh HJ, Hassan MH, Innes NP, Baik AA, Mossey PA. Parental consanguinity and nonsyndromic orofacial clefts in children: A systematic review and meta-analyses. Cleft Palate Craniofac J 2014;51:501-13.

7. Bittles AH, Black ML. Evolution in health and medicine Sackler colloquium: Consanguinity, human evolution, and complex diseases. Proc Natl Acad Sci U S A 2010;107 Suppl 1:1779-86.

8. Bittles AH, Black ML. Global Prevalence of Consanguinity; 2015. Available from: http://www.consang.net/index.php/Global_ prevalence. [Last accessed on 2015 Mar 20].

9. Kulkarni ML, Kurian M. Consanguinity and its effect on fetal growth and development: A South Indian study. J Med Genet 1990;27:348-52.

10. Mehndiratta MM, Paul B, Mehndiratta P. Arranged marriage, consanguinity, and epilepsy. Neurol Asia 2007;12:15-7.

11. Bittles AH, Black ML. The impact of consanguinity on neonatal and infant health. Early Hum Dev 2010;86:737-41.

12. Amudha S, Aruna N, Rajangam S. Consanguinity and chromosomal abnormality. Indian J Hum Genet 2005;11:108-10.

13. Rajabian $\mathbf{M H}$, Sherkat M. An epidemiologic study of oral clefts in Iran: Analysis of 1,669 cases. Cleft Palate Craniofac J 2000;37:191-6.

14. Jamilian A, Nayeri F, Babayan A. Incidence of cleft lip and palate in Tehran. J Indian Soc Pedod Prev Dent 2007;25:174-6.

15. Aziza A, Kandasamy R, Shazia S. Pattern of craniofacial anomalies seen in a tertiary care hospital in Saudi Arabia. Ann Saudi Med 2011;31:488-93.

16. Ravichandran K, Shoukri M, Aljohar A, Shazia NS, Al-Twaijri Y, Al Jarba I. Consanguinity and occurrence of cleft lip/palate: A hospital-based registry study in Riyadh. Am J Med Genet A 2012;158A: 541-6.

17. Naidu DL, Raju MS, Goel S. Effects of consanguineous marriages on oral and craniofacial structures: A study of dental patients in North India. Ann Essences Dent 2010;2:199-203.

18. Jose BA, Subramani SA, Mokhasi V, Jayan M. Consanguinity and clefts in the craniofacial region: A retrospective case-control study. J Cleft Lip Palate Craniofacial Anomalies 2015;2:113-7.

19. Bittles AH. Endogamy, consanguinity and community genetics. J Genet 2002;81:91-8.

20. Ghonmode SW, Kalaskar AR, Kalaskar RR, Chole R. Vista of cleft lip and palate in India. J Evol Med Dent Sci 2012;1:1097-106.

21. Bittles AH, Shami SA Appaji Rao N. Consanguineous marriage in Southern Asia: Incidence, causes, and effects. In: Bittles $\mathrm{AH}$, Roberts DF, editors. Minority Populations: Genetics, Demography, and Health. London: Macmillan; 1992. p. 102-8.

22. Jyothilekshmi P, Sudhakaran MV. Trends and prevalence of consanguineous marriages in Mudaliars of Palakkad district of the state of Kerala. J Hum Ecol 2012;38:1-5.

23. Nath A, Patil C, Naik VA. Prevalence of consanguineous marriages in a rural community and its effect on pregnancy outcome. Indian J Community Med 2004;29:41-3.

24. Dvivedi J, Dvivedi S. A clinical and demographic profile of the cleft lip and palate in Sub-Himalayan India: A hospital-based study. Indian J Plast Surg 2012;45:115-20.

25. Census India. Literacy and Level of Education in India; 2011. Available from: http://www.censusindia.gov.in/2011census/ population_enumeration.html. [Last accessed on 2015 Mar 22].

26. Bittles $\mathrm{AH}$, Black ML. Consanguineous Marriages in Asia; 2015. Available from: http://www.consang.net/images/c/cb/Asia.pdf. [Last accessed on 2015 May 20].

27. Census India 2011. Population Distribution by Religion in India. Available from: http://www.censusindia.gov.in/Ad_Campaign/ drop_in_articles/04-Distribution_by_Religion.pdf. [Last accessed on 2015 Mar 22].

28. Golalipour MJ, Kaviany N, Qorbani M, Mobasheri E. Maternal risk factors for oral clefts: A case-control study. Iran J Otorhinolaryngol 2012;24:187-92.

29. Shahin $H$, Sharaha $U$, Lee MK, Watts A, King MC, van Aalst J, et al. Targeted Capture and Sequencing Identify Causative Alleles in Simplex and Multiplex Consanguineous Palestinian Families with Orofacial Clefts. $63^{\text {rd }}$ Annual Meeting of the American Society of Human Genetics, Boston, USA; 22-26 October, 2013.

30. Butali A, Mossey PA. Epidemiology of orofacial clefts in Africa: Methodological challenges in ascertainment. Pan Afr Med J 2009;2:5.

31. Agrawal K. Clinical and demographic profile of cleft lip and palate in Sub-Himalayan India: A hospital-based study. Indian J Plast Surg 2012;45:120-1.

32. World Health Organisation. Global registry and database on craniofacial anomalies. Human genetics programme: International Collaborative Research on Craniofacial Anomalies. Geneva, Switzerland: WHO Publications; 2003.

33. World Health Organisation. Addressing the global challenges of craniofacial anomalies. Human genetics programme: Report of a WHO Meeting on International Collaborative Research on Craniofacial Anomalies. Geneva, Switzerland: WHO Publications; 2006. 